\title{
The Effective Measures to Improve Classroom Teaching Quality of Enginery
}

\author{
Shuqiong $\mathrm{Xu}$ \\ School of Mechanical Engineering, Linyi University, \\ Linyi, Shandong 276005, China \\ xushuqiong11@sina.com
}

Keywords: Effective Measures; Improve; Classroom Teaching; Quality; Enginery.

\begin{abstract}
There are some factors that affect the classroom teaching quality of Enginery, schools, teachers and students are the three most important factors. We can rely on the support of the school policy, the leading role of teachers and students' joint efforts. We should pay more attention to teach through the reformation of teaching contents, teaching methods, teaching means, evaluation system of students, and we should deepen the reform of practical teaching.
\end{abstract}

\section{Introduction}

School, teacher and student are the three most important factors that affect the classroom teaching quality. We can rely on the support of school policy, joint efforts of teachers and students to improve the quality of classroom teaching. We should innovate teaching content, improve teaching methods, pay more attention to the combination of theory and practice, reform the evaluation system of teacher and student.

\section{The support of school policy}

In the school policy, teachers should be encouraged to undertake teaching tasks actively, and every teacher must complete the required teaching tasks. In the academic title evaluation, we should give priority to the teachers who take teaching as the most important work. Teachers should understand the dialectical relationship between scientific research and teaching correctly: teaching can promote scientific research, scientific research can also deepen teaching [1] [2].

\section{The leading role of the teacher should be given full play to improve the teaching quality.}

Teachers' leading function in teaching mainly includes the following aspects:

3.1 Implementing the basic elements of the teaching process through careful preparation.

The realization of the teaching goals is mainly depending on the teachers' preparation and effective play in class.

Lectures, class discussions, work training, practical training, assessment and teaching materials are the six areas that constitute the basic paradigm of class teaching. These comprehensive requirements can not be replaced by a single modern educational technology, and especially the teachers' style, characteristics, direct communication with students and facing feedback of students cannot be replaced by any one of the modern education technology.

The teaching should combine with engineering examples, catastrophic engineering accidents and discipline development history and the process focus on inspiration, guidance and interaction, which can make students feel immense interest to learn and be able to put them into action.

3.2 Adopting the model, picture and object for teaching and putting $3 \mathrm{D}$ printing into classroom.

In the field of engineering technology teaching, the experienced teachers often brought some teaching aids to classroom. These educational tools have a strong visual and tactile impression effect in teaching. Through observation and tactile impression, students can form a comprehensive feeling 
and deepen the understanding of things. Exactly, it is more real, intuitive and vivid than the high level of virtual reality. Although virtual reality can mix the spurious with the genuine point, while the model, picture and object are real.

Students of engineering college reflect that the curriculum is too abstract to understand. Some mechanical structures, mechanical movement principles comprise a big problem for those students with poor spatial imagination ability. Therefore, the students play phone, play games, weariness are common occurrences in class. For those teachers engaged in machinery, the most difficult thing of teaching content is that teaching students to understand the structure and the basic principles of mechanical parts, the students only rely on charts, photographs, or other two-dimensional plane aids is difficult to imagine the shape, structure and motor function of components. With 3D printing technology gonging into the universities, it brings the gospel to students. The 3D printing technology is applied in teaching, so that students can mapping, modeling, print out a variety of classes appliances personally, which will help improve the students' enthusiasm and cultivate engineering consciousness and innovation ability. Application of 3D printing technology in the mechanism of professional teaching, will significantly improve the teaching quality of professional basic courses and professional courses. 3D printing is not only foster student interest in learning, but also to enable students to change from passive learning to active learning. Students in the form of team cooperation and discussion, active and actively start work and think about thing, in turn to enhance the students' team spirit, practice ability and innovation ability.

\subsection{Cultivate scientific thinking method}

Weichang Qian academicians have pointed out: "we hope that the students in the school is mainly to master a correct learning method, working methods and thinking method, it is the method of dialectical materialism, the curriculums or majors are the carrier ,we train everyone to master this method by the carrier."

Traditional classroom teaching that pay attention to the cultivation of the common thinking adopt the deduction and methods from the general to special, which introduce the concept in the first place, then derive the principle and explain the examples finally. On the basis of traditional classroom teaching, consideration is given to both the divergent thinking and converse thinking's cultivation. Why should we study, how to study, how to use and the cause of the problem must be taken into account. So that student could change learning methods from passive learning to active learning. In other words, while studying with problem, students could have a positive thinking, which can improve students' ability to discover problems, raise problems, analyze problems and solve problems. For example, students should thinking about that how to improve the stability of the compression bar in engineering practice when the teacher refer to the problem about the stability of compression bar. When we teach stress state, by the observation of experimental phenomena of tensile and torsion of low carbon steel and cast iron, we can put forward the question why we should study the stress state, and for the stress concentration, we should analyze its advantages and disadvantages, we not only can avoid stress concentration but also can make effective use of it in practical application [3] [4].

Teachers should consciously ask questions, just indicate the motions, not ask a question and answer it by himself, and should take elicitation methods to guide students to think actively, and use discussion-based teaching methods to lead students boldly to express their opinions. It is one of the most important responsibility for collage teachers to expand students' mind space and to cultivate the correct mode of thinking.

\subsection{The timely feedback of the teaching effect}

During the classroom instruction, teachers should always observe the students' demeanor expressions and the use of short-term small exercises, quizzes, etc to obtain the timely feedback of the teaching effect. And they can also through course website, E-mail, QQ instant messaging software, etc, to interact online in real-time. So they can adjust their teaching pace based on the students' mastery of the course content and the reflection of progress speed.

\subsection{Teachers should master some basic skills}

Despite a reduction of blackboard writing opportunities (including drawing) in modern educational technology, appropriate writing still helps to deepen the teaching process. When you draw a correct, 
standard pattern on the blackboard, the students could not only with admiring eyes, and there are plenty of thinking time [5] [6].

\section{We should deepen the reform of evaluation system of students.}

The management of the process shall be strengthened to ensure that students are buried in studies, achieving the aim of promoting the quality of education.

Correcting students' papers, test and final exam papers, teachers adhere to the grading standard, fairness, justice and free from outside interference, such as leadership, colleagues. In other words, teachers should have the courage to stick to principles. They should not change the score randomly. In addition, teachers should take a correct attitude, rigorous scholarship and dare to criticize the bad phenomenon of the students.

We should pay attention to assessment of student learning process, and strengthen the usual examination. According to the practice of foreign countries, increasing the times of unit test( Paper, a written examination, oral, etc.) and reducing the final exam results' proportion in comprehensive performance evaluation of single course could evaluate a student's learning situation impartially in a semester.

\section{We should deepen the reform of practical teaching}

We should Pay high attention to practice, improve students' practical ability. Make unremitting effort on the engineering training center and improve the teaching quality of engineering training and production practice.

In order to cultivate and improve students' practice and innovation ability, we must pay attention to the practical teaching link, such as experiment, practice and graduation design, especially the Professional practice and graduation practice. Take effective measures to ensure the students' practice time and quality, and promote the combination of teaching with the productive labor and social practice.

Due to the lack of recognizing the importance of engineering training, many students and even many schools think little of the practice engineering training. They don't want to put enough money into the construction project of engineering training center.

Engineering training is the first practical teaching link for students who major in mechanical, material, power, chemical machinery, electrical engineering and other engineering and technical professional to understand and recognize the factory and enterprise, and it's purpose is to learn the mechanical manufacturing process knowledge and grasp the machining process of rough manufacturing and parts. Engineering training include the introduction of equipment, tools and processes, as well as the specification, the operation essentials and safety technology, etc.

These vivid and specific content which is visible, tangible and closely integrated with the actual production displayed in front of the students visually, and it can help students to master basic knowledge and some of the basic theory and skill. Students can enhance the actual working ability and acquire and consolidate the perceptual knowledge through practical operation, which can lay the necessary foundation for the future course of study and the work involved in mechanical design and manufacturing.

The teacher should also combine the concrete practice content to give students some difficulty questions, and the purpose is to guide students to observe the scene, inspire independent thinking, and cultivate the ability to analysis and solve problems. In order to solve these problems, students not only need to read textbooks, but also need to go to the scene to examine the material and technical document and consult internship instructor, so as to preliminary cultivate the ability to solve problems in practical work.

For the sake of learning course, based on students' learning basic course and technology class, production practice making the student to integrate theory with practice is specifically set for students. In the production practice, the students acquaint all kinds of specific technical operation and the 
perceptual knowledge of all kinds of basic technical equipment, it directly lay the perceptual knowledge foundation for specialized course learning.

From the experiment, curriculum design and engineering practice, cognition practice, production practice and skill training to the graduation, our school built the systematic practice teaching system. What is more, we make theory, practice experiment, design , training course system perfect and strengthen the link of practice and innovation quality cultivation .It make the students realize the systematic training of design and Practice(training) from the first term to the eighth term, and obtaining the better practice teaching effect [7] [8] [9] [10].

\section{We should stimulate students' professional interests}

We should stimulate students' professional interests, improve students' learning motivation and guide students to establish lofty ideals, love learning, dare to explore. Good style of study is prerequisite to achieve good teaching quality [11] [12].

\section{Teachers should enforce the examination discipline strictly and deal with cheating student seriously, so that can we establish a good examination atmosphere.}

\section{Summary}

It is a hard work to improve the classroom teaching quality of Enginery, which need the support of the school policy, teachers' dedication and student's efforts, the three parties ensure the high teaching quality.

\section{References}

[1] Q.S.Fan, Improving the quality of classroom teaching is the key to high quality Education, China University Teaching, vol. 11, 2003.

[2] J. X. Yu, Promoting the reform of engineering education and striving to cultivate high quality engineering talents, China University Teaching. vol. 04, 2014.

[3] D. Q, Chen, Practice of cultivating students' creative ability and innovative spirit, Mechanics and Engineering, vol. 05, 2004.

[4] ZH. M. Ye, Application of scientific thinking and scientific method in the teaching of mechanics and Engineering,China University Teaching, vol. 06, 2011.

[5] ZH. M. Ye, The basic work on a basic mechanics course of Teachers, Mechanics and Engineering, vol. 03, 2005.

[6] ZH. M. Ye, The basic qualities of a good university teachers, China University Teaching, vol.11, 2006.

[7] S. G. Fu, Creating a engineering practical teaching system with Chinese characteristics, China University Teaching, vol. 07, 2004.

[8] Y. J. Xing and W. Zhao, Deepening the reform of the practice teaching and forming the educating atmosphere, China Higher Education, vol. Z2, 2012.

[9] J. Lin, Constructing engineering practical education system and cultivating outstanding engineers, China Higher Education, vol. Z2, 2012.

[10] X. H. Zhang, Creating practical teaching platform to improve students' innovation ability, China Higher Education, vol. 06, 2012.

[11] J. X. Yu, Improving the learning motivation of undergraduates and cultivating outstanding talents, China Higher Education, vol. Z3, 2013.

[12] S.Z. Yang, Discussed about really grasping the quality of classroom teaching once again, Research in Higher Education of Engineering, vol.02, 2008. 